\title{
La financiación de las Regiones Autónomas de la Costa Atlántica de Nicaragua mediante recargos
}

Héctor Zacarías Méndez Morales

Estudiante de Derecho con mención en Derecho Económico, Universidad Centroamericana.

Dirección: Edificio Armando Guido 4 cuadras al Sur, 1 cuadra al Este, Managua, Nicaragua. Tel: (505)8864-3111.Correo electrónico: hectormendezm@hotmail.com

\section{Recibido: febrero de 2010 / Aceptado: febrero de 2010}

LA INDISCUTIBLE DIFERENCIA HISTÓRICA, CULTURAL Y SOCIAL ENTRE LA POBLACIÓN del Caribe y el resto del país ha significado un óbice para la integración social y económica de los ciudadanos en el progreso material de la nación, así como conflictos y discordias para ambos sectores territoriales. Esta situación condujo en 1987 al reconocimiento de un régimen de autonomía regional que garantice y respete el ejercicio efectivo de los derechos de las comunidades de la Costa Atlántica, consignados en nuestra Constitución Política.

El precepto surgido dos décadas atrás perfiló la concreción de los derechos humanos, culturales, económicos, sociales y políticos de casi el 10\% de la población. El interés decayó con el transcurso de los años por parte de los gobiernos de turno, surgiendo una serie de circunstancias que entorpecen una real autonomía territorial jurídicamente reconocida, así como una autonomía financiera regional que garantice un autogobierno responsable, de competencias públicas, y en su territorio, capaz de sufragar sus gastos y perseguir los fines del Estado Social de Derecho.

Es por ello que urge la búsqueda y consecución de fuentes de ingreso para las regiones del Caribe nicaragüense que proporcionen la suficiencia financiera de los gobiernos regionales en aras de afianzar su autonomía, cumplir los preceptos constitucionales y derechos fundamentales que demandan el desarrollo integral de la región, y que permita la plena inclusión de la población nicaragüense del Caribe en el tejido social y económico de una nación llamada a conformar un Estado social de Derecho unitario e indivisible.

Palabras clave: tributario / impuesto / recargo / financiación

\section{Introducción}

La presente investigación se realizó con motivo del "IX Encuentro de Jóvenes Investigadores" de la Universidad Centroamericana. Teniendo en consideración ciertos aspectos -que a lo 
largo del estudio expondré- respecto a la realidad económica, política, social y jurídica de Nicaragua, consideré que era urgente desarrollar una propuesta para la defensa de la Autonomía Regional de las Regiones Autónomas de la Costa Atlántica desde una perspectiva jurídico-económica, que contribuya al desarrollo de nuestro país.

Indudablemente, el reconocimiento de la Región Autónoma del Atlántico Norte y la Región Autónoma del Atlántico Sur bajo un régimen de autonomía constituyó no sólo un logro a nivel nacional, sino que perfiló a Nicaragua, desde una perspectiva latinoamericana, como pionera en la materia.

Sin embargo, desde la creación de tales regiones, éstas han carecido de fuentes de financiación propias que les permitan a los gobiernos regionales administrarse bajo un verdadero régimen de autonomía, trayendo como resultado una dependencia, en términos financieros, del gobierno central. Esto se traduce en una limitación de su terreno de actuación desde hace más de 20 años.

Ello nos hace ver la urgencia del tema, ya que nos referimos a una extensión territorial equivalente a aproximadamente el 50\% del territorio nacional, cuyo desarrollo pasa inadvertido, donde su población ha sido absorbida por una pobreza progresiva durante más de dos décadas. Mientras, el resto del país permanece inerte ante esta situación que atenta en contra de los mismos derechos fundamentales de sus pobladores.

Es por todo ello que se hace necesaria la búsqueda y consecución de la suficiencia financiera de las Regiones Autónomas de la Costa Atlántica, que les permita gozar de una autonomía política, administrativa y financiera, para arremeter en contra de estas injusticias históricas.

\section{Objetivos}

\section{Objetivo general}

Analizar las implicancias jurídicas de la autonomía financiera de las Regiones Autónomas de la Costa Atlántica de Nicaragua y su financiación mediante recargos

\section{Objetivos específicos}

1. Estudiar la autonomía territorial y sus implicancias.

2. Analizar jurídicamente las Regiones Autónomas de la Costa Atlántica.

3. Escrutar la problemática que se genera en torno a la financiación tributaria de las Regiones Autónomas de la Costa Atlántica.

4. Definir la figura jurídica de los recargos o sobreimpuestos, así como su naturaleza, características e importancia. 
5. Observar, identificar y meditar respecto de la aplicabilidad de los recargos en Nicaragua como medio de financiación a las Regiones Autónomas de la Costa Atlántica y sus beneficios.

\section{Metodología}

Para el desarrollo del estudio se empleó una metodología investigativa, documental y analítica, que nos permitió apreciar la problemática en torno al tema e idear una solución jurídica viable.

\section{Discusión}

Se pretende determinar la idoneidad de la implementación de recargos en Nicaragua como medio de financiación para disminuir la desigualdad económica real de las Regiones Autónomas de la Costa Atlántica respecto del resto del país, sin que ello consista un quebrantamiento del Sistema Tributario Nicaragüense, respetando las disposiciones constitucionales que rigen la autonomía financiera de los Gobiernos Regionales a través de fuentes propias de financiación.

\subsection{La autonomía territorial en el Estado de Nicaragua}

Podemos afirmar sin temor a equivocarnos que las Regiones Autónomas de la Costa Atlántica fueron creadas bajo un concepto asistemático que provoca ciertas "irregularidades" calificables de sui generis. Es precisamente por inconvenientes como este que antes de acometer al tema a tratar es menester dar una mirada a ciertas pautas delineadoras de nociones generales, tales como autonomía territorial, autonomía financiera y poder tributario, sin olvidar, claro está, introducir la figura de los recargos como pilar del presente estudio y su aplicación en Nicaragua.

\section{Definición de Autonomía Territorial}

Por este término debemos entender "la potestad que dentro del Estado pueden gozar municipios, provincias, regiones u otras entidades de él, para regir intereses peculiares de su vida interna, mediante normas y órganos de gobierno propios. En este sentido, la autonomía supone la unidad de los entes autónomos dentro del estado único. Se trata simplemente de una descentralización administrativa y política, que no debe confundirse con lo que en un Estado federal representan las provincias o Estados miembros (...)" (Cabanellas \& Ossorio, 2007). En este concepto, que tomamos prestado de Cabanellas y Ossorio, convergen nociones como región, normas, gobierno, descentralización administrativa, entre otros, que nos exponen las implicancias del término, siendo esta denominación la mayormente aceptada para definir autonomía ${ }^{1}$.

De lo anterior podemos deducir que el concepto de Autonomía Territorial implica cierto grado de decisión sobre las materias administrativas propias, por parte de las autoridades correspondientes, que les permita regir los intereses de su vida interna, para lo cual se revela de singular importancia el contar con ingresos propios que amplíen el campo de decisión de sus autoridades. 
En este mismo sentido se refiere Escorcia (2009, pp. 323-332), quien entiende por Regiones Autónomas a aquellos entes públicos territoriales con facultades políticas de autogobierno reconocidas por la Constitución, que se encargan del desempeño auto-responsable de competencias publicas en su territorio. A su vez, hace énfasis en el no sometimiento al control de otro ente superior en lo que suponga una tutela de la oportunidad de sus decisiones.

\section{Marco jurídico de la autonomía regional nicaragüense}

En el caso particular de Nicaragua, de manera loable se reconoció, por medio de la actual Constitución Política del país ${ }^{2}$, el respeto a la tradición histórica y cultural de las comunidades indígenas de la Costa Atlántica, a través de un régimen de Autonomía Regional ${ }^{3}$, el cual se vio respaldado inmediatamente por la aprobación, el 7 de septiembre de 1987, de la Ley No. 28, denominada Estatuto de Autonomía de las Regiones Autónomas de la Costa Atlántica $^{4}$ (La Gaceta, 1987). Por medio de dicho estatuto se crean dos regiones: Región Autónoma Atlántico Norte y Región Autónoma Atlántico Sur, también conocidas como RAAN y RAAS respectivamente, a las cuales se les atribuye, entre otras cosas, el establecer impuestos regionales conforme las leyes que rigen la materia ${ }^{5}$, la elaboración de proyectos de presupuesto de su región ${ }^{6}$ y hasta la elaboración del Plan de Arbitrios de cada región mediante su respectivo Consejo Regional ${ }^{7}$. Todo ello, evidentemente, en concordancia con los conceptos generales inherentes a la Autonomía Territorial antes abordados.

Vemos entonces dibujado el marco inicial sobre el cual se estructuraban estas dos Regiones Autónomas equivalentes a una superficie aproximada de $60,366.00 \mathrm{~km}^{2}$ y una población equivalente a 619,819 habitantes ${ }^{8}$. El panorama dio un giro de 360 grados cuando el 1 de febrero de 1995 se aprueba la Ley No. 192, Ley de Reforma Parcial a la Constitución Política de la República de Nicaragua (La Gaceta, 1995), por medio de la cual se le reconoce a las Regiones Autónomas una serie de derechos que sin duda vienen a afianzar la autonomía regional, tales como: la atribución a los Consejos Regionales de aprobar las concesiones y contratos de explotación de los recursos naturales dentro del territorio regional ${ }^{9}$, si bien, a su vez la atribución de iniciativa de ley por parte de los Consejos Regionales ${ }^{10}$.

A pesar de todo ello, el precio de estos reconocimientos fue mayor que los beneficios recibidos, ya que se despojó a las Regiones Autónomas de un régimen de autonomía stricto sensu, citado supra, al reformar el artículo 114 de la Constitución, disponiendo que "Corresponde exclusivamente y de forma indelegable a la Asamblea Nacional la potestad para crear, aprobar, modificar o suprimir tributos. (...)”, disposición que deroga tácitamente, cualquier noción de potestad tributaria normativa derivada que podríamos haber deducido de los artículos 8 inc. 9 y artículo 23 inc. 2 del Estatuto de Autonomía antes referido, derogación que se proyecta sobre la facultad regional de creación de impuestos regionales, así como elaboración del Plan de Arbitrios.

Con esta reforma constitucional se redujo el ámbito de autonomía regional en el estricto apartado tributario, el cual, por definición forma parte del ámbito financiero, arista fundamental dentro de cualquier régimen de autonomía junto con los aspectos administrativos y políticos. Este hecho no nos puede hacer perder de vista que las Comunidades de la Costa Atlántica forman parte indisoluble del Estado unitario e indivisible de Nicaragua ${ }^{11}$. 
Todo este entorno y la carencia de una reglamentación de la Ley 28, generó que la dinámica del accionar de los gobiernos regionales gire en torno a los recursos provenientes de las transferencias presupuestarias del Presupuesto Nacional de la República ${ }^{12}$, lo que se traduce en una dependencia financiera directa de las transferencias presupuestarias del gobierno central.

Finalmente, el 9 de julio de 2003 fue aprobado el Reglamento a la Ley No. 28 (La Gaceta, 2003), sobre el cual no hay mucho que comentar puesto que, una vez consolidadas las trabas constitucionales, como era de esperarse, el Reglamento se limitó a conceptualizar y desarrollar la Ley No. 28 sin referencia relevante a la materia tributaria.

\subsection{Poder Tributario y autonomía financiera}

Con rotundidad es posible afirmar que el Poder Tributario consiste en una manifestación de soberanía por parte del Estado ${ }^{13}$, lo que nos remite a la territorialidad y justifica la sujeción de los contribuyentes dentro de esta delimitación. Tal y como apunta Balladares Saballos (2008), éste supone la potestad del Estado para crear, aprobar, modificar y aplicar el sistema tributario. Consecuentemente, siguiendo la misma línea, el Poder Tributario implica tanto la potestad tributaria normativa, así como la potestad de imposición ${ }^{14}$.

Podemos apreciar de lo anterior la proyección del tributo como manifestación de la soberanía residente en el pueblo, a través del ejercicio del poder tributario por medio de los representantes legítimamente electos, tributo que, en palabras de Amatucci (2001, pp. 623624) se configura como:

...deber cívico del contribuyente de solidaridad en el sufragio de los gastos públicos en razón de su capacidad contributiva ${ }^{15}$, a efectos de que el Estado cumpla con los deberes inderogables de solidaridad pública, económica y social, en el marco del respeto al deber ciudadano de desarrollar según las propias posibilidades o según su opción, una actividad o función que concurra al progreso material o espiritual de la sociedad...

Siguiendo con este lineamiento, el Derecho Tributario debe una fiel sujeción a una serie de criterios de justicia, erigiéndose sobre principios inspiradores del justo reparto de la carga tributaria (principio de capacidad contributiva ${ }^{16}$ ); criterios de igualdad que supongan una corrección a las desigualdades existentes en la sociedad (principio de igualdad tributaria ${ }^{17}$ ); y aportaciones que sugieran una justificación altruista a los efectos de la realización del bien común (principio de solidaridad); entre otros.

Así, habiendo introducido elementos como la diversidad de potestades que se derivan del poder tributario y los diversos principios de justicia tributaria, de entre los cuales podemos destacar el principio de solidaridad, que prima como deber cívico del contribuyente y se fundamenta en la soberanía estatal y el sufragio de los gastos públicos, nos preguntamos el papel que juega la autonomía financiera en todo esto.

Debemos entender por autonomía financiera la atribución de capacidad de gasto, endeudamiento y participación en los ingresos del Estado, que permita regir los intereses 
de la vida interna del ente público, para lo cual se le deberá garantizar ingresos en partidas presupuestarias de egresos suficientes, que no suponga una tutela de la oportunidad de sus decisiones.

No obstante, la reserva absoluta del Estado respecto al poder tributario ${ }^{18}$ que hemos venido desarrollando, autores como Calvo Ortega (1997, p. 123) se refieren a seis funciones contenidas dentro de dicho poder: establecimiento de tributos, potestad reglamentaria, de organización, de interpretación, de decisión de pretensiones contra la propia gestión y actividad de inspección. Estas funciones nos facilitan el entendimiento de la naturaleza misma del poder tributario, en términos teleológicos.

Resumiendo los diversos puntos arriba analizados, podemos sostener que la Autonomía Financiera implica el participar en los ingresos del Estado, en partidas presupuestarias de egresos suficientes para la realización del fin último de los tributos, el cual se traduce en el "sufragio de los gastos públicos para el progreso material y espiritual de la sociedad" (Amatucci, 2001, pp. 623-624). Sin embargo, la actividad financiera de las Regiones Autónomas de Nicaragua se ha visto obligada a girar en torno al Presupuesto General de la República, dependiendo completamente de la partida presupuestaria que le sea asignada.

Todo lo anterior nos lleva a optar por los recargos, como institución jurídico tributaria idónea, a los efectos de lograr una autonomía financiera efectiva para las Regiones Autónomas del Caribe nicaragüense.

\subsection{Los recargos como fuente de financiación}

\section{Naturaleza Jurídica}

"Los recargos son tributos que se superponen a otros ya existentes, de forma tal que coexisten dos gravámenes con un mismo hecho imponible” (García Frías, 1994, p. 26) (entendido como el hecho generador de la obligación jurídico-tributaria), de lo cual se desprende que habrá una coincidencia respecto al hecho imponible y sujeto pasivo, mas no respecto al sujeto activo, según explicaremos más adelante ${ }^{19}$.

Los recargos se implementan de manera temporal o permanente a cierto sector territorial para financiar (bajo el principio de solidaridad) otro territorio distinto que necesite fuentes de esta índole, consistiendo en una sobreimposición establecida mediante ley, de naturaleza meramente tributaria, aplicada a la cuota de un impuesto base ya existente. Es por estos mismos motivos que se recomienda denominarlos sobreimpuestos, denominación técnicamente más acendrada ${ }^{20}$.

\section{Estructura Jurídica}

Antes de avanzar a la materia que nos compete, debemos detenernos a hacer un estudio conceptual de lo que podríamos entender por impuesto base y cuota, siendo el primero cualquier impuesto ya existente en nuestro ordenamiento jurídico ${ }^{21}$. Por otro lado, la cuota, de acuerdo a Pérez Royo (2001, p. 185), es “el momento final de la cuantificación del tributo 
en cuestión, la cual se obtiene de la conjugación de los demás elementos constitutivos del tributo", lo que, en pocas palabras, significa la obligación cuantificada.

Habiendo aclarado esto, podemos apreciar cómo la configuración jurídica de los recargos, nos remite a una estructura que supone "la sobreimposición de un mismo índice de capacidad contributiva, de forma simultánea, por dos figuras tributarias" (García Frías, 1994, pp. 140-142). Por lo cual, a pesar de tener una naturaleza jurídica tributaria, el criterio diferenciador de un sobreimpuesto frente a otras formas de sobreimposición se halla en que éste utiliza un hecho imponible previamente cuantificado, mientras que las otras formas de sobreimposición poseen hechos imponibles propios, similares a otros ya existentes ${ }^{22}$.

Para determinar los elementos constitutivos de los recargos, debemos tener siempre presente el impuesto base sobre el cual sea aplicado, ya que éstos cuentan con numerosas concomitancias, excepto el sujeto activo, sobre el cual hay que prestar especial atención y recurrir ineludiblemente a la tripartición germánica (a esta tripartición se refiere García, 1994, pp. 75-78):

- Competencia normativa (potestad tributaria normativa): forma parte integral del Poder Tributario del Estado, tal y como pudimos apreciar líneas arriba. Sin embargo, ésta se refiere específicamente a la potestad de dictar normas jurídico-tributarias como expresión de soberanía, la cual, en el caso de Nicaragua, le corresponde de acuerdo al artículo 114 Cn. a la Asamblea Nacional.

- Competencia administrativa (potestad de imposición): al igual que la anterior, constituye parte integrante del Poder Tributario, limitado a la liquidación, gestión y recaudación de los tributos establecidos por medio de la potestad tributaria normativa. En este caso le corresponderá al Poder Ejecutivo por medio de la Dirección General de Ingresos (DGI) y la Dirección General de Servicios Aduaneros (DGA), o bien a las respectivas Direcciones de Recaudación adscritas a las municipalidades, todo en dependencia del tributo en cuestión ${ }^{23}$.

- Competencia sobre los rendimientos (el sujeto activo sobre los frutos de la recaudación): no obstante esta noción nos remita al ámbito del derecho presupuestario, reviste especial importancia a efectos del presente estudio. En el caso de Nicaragua se configuraría a las autoridades regionales ${ }^{24}$ como sujeto activo sobre los frutos de la recaudación, respecto al recargo que propondremos. Resumiendo en pocas palabras, dichas autoridades regionales administrarían los rendimientos de los tributos establecidos por quien ostente la potestad tributaria normativa, y recaudados por el correspondiente a la potestad de imposición, que se traduce en un sujeto activo de la obligación jurídico-tributaria.

Siguiendo esta línea debemos perfilar una nítida separación entre el destino de los rendimientos del impuesto base y el recargo, sin perjuicio de la coincidencia de la potestad normativa e impositiva. 


\subsection{Aplicación de los recargos en Nicaragua y sus ventajas}

Existen ciertos inconvenientes imposibles de ignorar en torno a la implementación de los recargos como medio de financiación. Éstos, en su mayoría, son inspirados por el carácter desincentivante de los tributos, y en mayor medida, al traducirse en una sobreimposición respecto de una misma manifestación de capacidad contributiva, lo cual ineludiblemente genera cierto rechazo o resistencia por parte de los contribuyentes.

Sin embargo, siendo evidente la necesidad de buscar medios de financiación para las Regiones Autónomas de la Costa Atlántica, antes de optar a la creación de un nuevo impuesto regional ${ }^{25}$, consideramos mayormente idóneo y beneficioso la aplicación de un recargo sobre el IR. Esto supone una menor resistencia psicológica por parte del contribuyente para su pago, e incluso administrativa, ya que tal y como nos manifiesta Calvo Ortega (1997, p. 221) no se hará una nueva cuantificación ni se gravará una nueva manifestación de capacidad contributiva. Se podrá recaudar conjuntamente por la misma Administración Tributaria ${ }^{26}$ con el impuesto base (IR), sin incurrir en nuevos gastos para su gestión.

Se aplicará entonces un Recargo con carácter permanente al Impuesto sobre la Renta (IR) a nivel nacional, tanto a las personas jurídicas como a las naturales, sean éstas asalariadas o no asalariadas ${ }^{27}$, constituyéndose como sujeto activo de los rendimientos del mismo a los Consejos Regionales ${ }^{28}$, recaudándose de forma conjunta con el impuesto base ${ }^{29}$, de tal manera que se grave con un porcentaje $\mathrm{X}^{30}$ adicional a los contribuyentes del IR.

Empero, siendo nuestro fin proporcionar una suficiencia financiera al Caribe, debemos idear todo un engranaje legal, eficiente y en pro de los principios de justicia tributaria, que cumpla con nuestra empresa. Por consiguiente, se deberá aplicar una deducción en el mismo porcentaje X recargado a los contribuyentes del IR residentes domiciliados ${ }^{31}$ dentro del territorio de la RAAN o la RAAS, la cual tal y como afirma García Frías (1994, p.58) "afecta al impuesto base pero nunca el sobreimpuesto".

Todo esto se traduce en suprimir por completo (en forma de deducciones en la cuota) la sobreimposición en las Regiones Autónomas de la Costa Atlántica, de tal manera que si establecemos un recargo del $1 \%{ }^{32}$ sobre el IR, deberemos establecer conjuntamente una deducción del mismo 1\% sobre este impuesto a quienes posean su domicilio fiscal dentro del territorio autónomo. Consecuentemente, el contribuyente tributará el mismo porcentaje que le correspondería de acuerdo a la Ley de Equidad Fiscal vigente, sin generar un aumento en la tributación.

En definitiva, podemos explicarnos por medio de un ejemplo hipotético aplicando un recargo del 1\% en el caso de una persona física (no asalariada) de la RAAN que perciba una renta anual gravable de C $\$ 350,000.00$. De acuerdo con la tabla progresiva del artículo 21 de la Ley de Equidad Fiscal, en dicho caso el porcentaje aplicable será del 25\% sobre C\$50,000.00 más $\mathrm{C} \$ 40,000.00$ de impuesto base, resultando una cuota total de $\mathrm{C} \$ 52,500.00$ anuales a favor del fisco en razón de IR. Es precisamente sobre esta cuota a pagar ${ }^{33}$ que aplicaríamos un recargo del 1\% para la Financiación de las Regiones Autónomas de la Costa Atlántica, resultando en C\$525.00 a favor de los Consejos Regionales y una deducción del mismo 1\% 
sobre la cuota del impuesto base (IR) a los contribuyentes con domicilio fiscal en cualquiera de las regiones del Caribe (en otras palabras, aplicamos las deducciones a todo el que sea gravado con recargos cuya residencia fiscal se encuentre en el territorio de las Regiones Autónomas del Atlántico Norte o Sur) lo que resultaría en los mismos C\$525.00, creando una ilusión jurídica para hacer un traslado constante y estable del 1\% del IR, rendimiento que se trasladaría del gobierno central en favor de los gobiernos regionales vía presupuesto pblico.

En el caso de los contribuyentes con domicilio fiscal en el resto del país, ajeno a los territorios regionales autónomos, el recargo operará bajo el principio de solidaridad, el cual tiene como contenido una idea de mutua ayuda, de asistencia recíproca y cooperación con otros sujetos para la consecución de un fin común (véase Moschetti, 1980, p. 113; Moschetti, 1973, p.69; y Liccardo, 1967 citado por Balladares Saballos, 2008).

Este principio se encuentra integrado por tres elementos constitutivos a los cuales hace referencia Moschetti (1980, pp. 116-117):

i. $\quad$ El sacrificio parcial de un interés individual;

ii. La ausencia (o la accidentalidad) de una contraprestación directa;

iii. El fin de interés colectivo.

En pocas palabras, se instituye un sujeto obligado a sacrificar su interés individual para hacer frente al interés de la colectividad en la medida en que falte (o sea accidental) una contraprestación directa. Esto presupone la permanencia de una organización económica privada junto a la organización pública y una distribución distinta de la riqueza en el interior de la economía privada. En caso contrario no habría sujetos obligados a un deber de solidaridad económica, ni sujetos beneficiarios de tal deber (Moschetti, 1980, p. 298; Moschetti, 1973, p. 260; véase también Escribano López, 1988, p. 195 citado por Balladares Saballos, 2008).

Resumiendo, los contribuyentes que generen renta neta de fuente nicaragüense, sea esta de bienes o activos existentes en el país; de servicios prestados a personas en territorio nacional, aún y cuando el que brinde el servicio no haya tenido presencia física; o de negocios llevados a cabo o que surtan efectos en la República de Nicaragua ${ }^{34}$, siempre y cuando no sean residentes domiciliados dentro del territorio de las Regiones Autónomas del Caribe, tributarán el IR actualmente establecido, más un recargo sobre la cuota de dicho impuesto, correspondiendo los rendimientos de lo recaudado en razón de IR al Gobierno Central y los rendimientos de lo recaudado en razón de Recargo a los Gobiernos Regionales.

En cambio, los contribuyentes con su domicilio fiscal dentro de las Regiones Autónomas de la Costa Atlántica seguirán tributando únicamente la misma cuota que tributan en la actualidad en razón del Impuesto Sobre la Renta, de acuerdo con la Ley de Equidad Fiscal y sus reformas vigentes, puesto que serán gravados con un recargo deducible en la misma cantidad. En este último caso, los rendimientos de lo recaudado se dividirán de la siguiente manera: lo que se hubiese ${ }^{35}$ recaudado en razón de recargo, corresponderá al Gobierno Regional de la circunscripción del contribuyente y el resto corresponderá al Gobierno Central. 
He aquí la importancia de establecer el recargo a nivel nacional aplicando deducciones en la RAAN y la RAAS, ya que al gravar a los residentes del Caribe con el recargo, a pesar de ser éste deducido en su totalidad, nos permite cuantificar la obligación jurídico-tributaria referente al mismo, en términos simples, lo que el sujeto pasivo hubiese tributado, en razón de recargo, en caso de tener su domicilio fiscal fuera de las Regiones Autónomas.

Esta cuantificación, nos hace posible determinar con exactitud el porcentaje de lo recaudado en las Regiones Autónomas del Caribe, en razón de IR, que será trasladado al Gobierno Regional de la RAAN y al Gobierno Regional de la RAAS para su financiación sin perder de vista que, a mayor renta producida por residentes de una región, mayores serán los rendimientos percibidos por las autoridades de gobierno local para sufragar los gastos públicos internos. Ello obliga a dichos gobiernos (entiéndase, Gobierno Regional de la RAAS y Gobierno Regional de la RAAN, respectivamente) a llevar a cabo una política responsable, que fomente el desarrollo de actividades económicas dentro de su territorio y no solo el esperar por los recursos proveniente del resto del país.

Todo ello se simplifica en la siguiente tabla mediante el uso de variables, las cuales aclaramos, representan valores, no conceptos. Dicha tabla nos permite apreciar que el mismo valor gravado en razón de recargo, corresponderá a los rendimientos destinados a los Gobiernos Regionales.

Tabla 1. Aplicación de los recargos y deducciones

$$
\begin{array}{ll}
X \square H & Y \square H \\
X \square Y & X=Y+H \\
\hline
\end{array}
$$

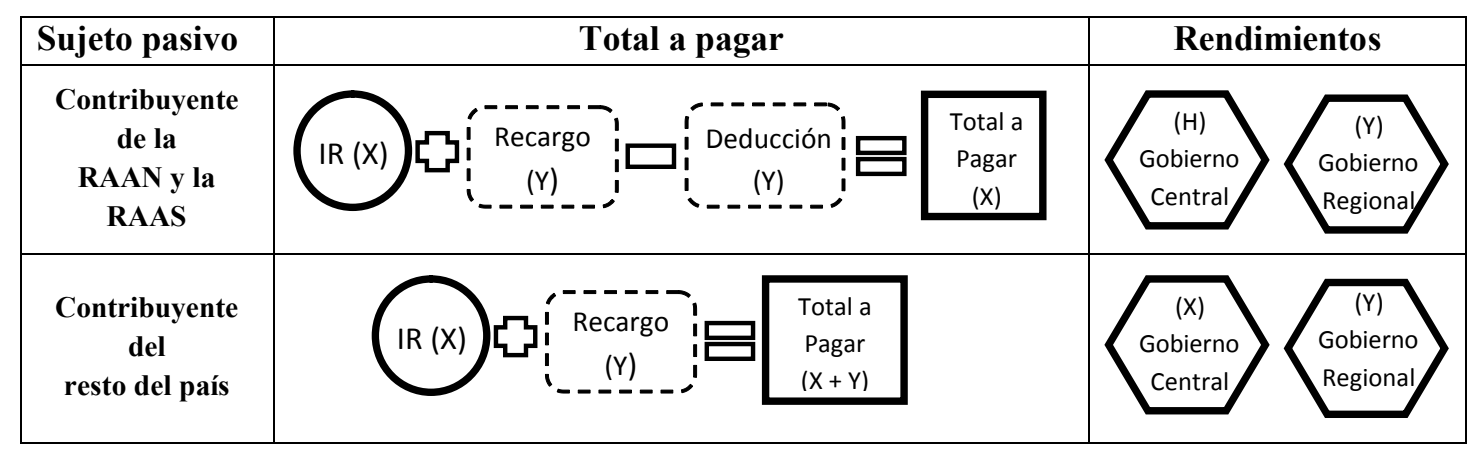

Vemos entonces cómo configuramos un recargo (sobreimpuesto) sin que signifique una sobre-imposición para el Caribe $^{36}$, gravando únicamente con una sobreimposición al resto del país de manera solidaria. Todo ello trae consigo un sinnúmero de ventajas. No significará un aumento en el grado de tributación para la población de las regiones que pretendemos financiar. Nos permitirá un mayor grado de aceptación por parte del sentir social, sin constituir una elevación pura y simple del tipo de gravamen. También permitirá aumentar la recaudación fiscal a favor de la RAAN y la RAAS, sin significar un aumento en el gasto administrativo relevante, ya que se recaudará conjuntamente con el impuesto base. Evitaremos posibles conflictos de doble-imposición que se generarían con el establecimiento 
de nuevos tributos que puedan coincidir o acercarse al hecho generador gravado por otros tributos nacionales preexistentes ${ }^{37}$; Finalmente, podremos lograr una mayor coordinación financiera expresada por medio de una participación por parte de las Regiones Autónomas en los ingresos del Estado, sin que signifique una dependencia financiera respecto al gobierno central, respetando la integridad indivisible del Estado nicaragüense.

Además de todo lo antes dicho, justificamos la implementación de los recargos como medio de financiación en Nicaragua, de un simple análisis a la afirmación hecha por Calvo Ortega, quien explica que en España "desde que se ha otorgado capacidad normativa a las Comunidades Autónomas, generando la modificación del tipo de gravamen de los tributos cedidos, el establecimiento de recargos ha perdido sentido" (1997, p. 222). Por ende, siendo que en Nicaragua los gobiernos regionales carecen de esta potestad tributaria normativa derivada, tal y como hemos afirmado en reiteradas ocasiones, vemos reflejada en mayor medida la necesidad de recurrir a esta figura jurídica.

Finalmente, con la aplicación del recargo y la deducción al IR en los términos antes detallados, incentivaremos la industria, el comercio y las demás actividades económicas en las regiones autónomas, sin significar el otorgamiento de beneficios tributarios, los cuales se traducirían en menos recaudación a favor del fisco, por consistir en una minoración de la carga tributaria. En cambio, en el caso propuesto se aplicará un recargo en el Pacífico y Centro del país que será deducido en el Atlántico, atrayendo la inversión a las regiones del Caribe.

\section{Conclusiones}

Como corolario de todo lo antes expuesto podemos concluir que los recargos o sobreimpuestos constituyen una fuente de financiación viable para las Regiones Autónomas de la Costa Atlántica de Nicaragua. Para ello se deberán realizar las reformas correspondientes a la Ley de Equidad Fiscal y su Reglamento, y la inclusión del resultado en la ley anual de presupuesto público.

A su vez, su implementación aseguraría la autonomía financiera de los gobiernos regionales, promoviendo un desarrollo coordinado con el resto del país, respetando la unidad e indivisibilidad del Estado que proclama nuestra Constitución Política en su artículo 6, el cual dispone que: "Nicaragua es un Estado independiente, libre, soberano, unitario e indivisible."

Este medio de financiación no sólo cumple su fin último sino que trae aparejada una serie de ventajas, tales como: evitar supuestos de doble imposiciones que se podrían generar con la creación de nuevos tributos; reducir los gastos, ya que se recaudaría conjuntamente con el impuesto base; crear una ilusión tributaria que genere mayor aceptación que una simple elevación del gravamen o la creación de un nuevo impuesto independiente.

Como colofón, además de todo lo antes deducido, podemos afirmar que por medio de la implementación de un recargo sobre el IR a los contribuyentes ajenos a las Regiones Autónomas de la Costa Atlántica, fundado bajo el principio de solidaridad, fomentamos una 
visión de país en los nicaragüenses que permita una mayor integración de culturas, auxiliada por la homologación de economías, así como la incentivación a desarrollar actividades económicas dentro de las regiones que permita un mayor flujo de personas.

Como resultado del presente estudio hemos logrado idear una fuente de financiación a favor de a las Regiones Autónomas de la Costa Atlántica configurada de acuerdo al ordenamiento jurídico de Nicaragua y en defensa de la autonomía financiera del Caribe.

\section{Agradecimiento}

Agradezco en particular al Dr. Reynaldo Balladares Saballos por su tutoría en el presente estudio durante el IX Encuentro de Jóvenes Investigadores.

\section{Notas}

1 Otras fuentes generales como RAE (2001) se prenuncian casi literalmente en el mismo sentido; o bien existen otros que se acercan grandemente: "Potestad que dentro del Estado tiene una entidad política o administrativa para dictar, por medio de un gobierno propio, las leyes que regularan sus intereses peculiares" (García-Pelayo \& Gross, 1994). Esta misma tendencia encontramos en diccionarios italianos al definir Autonomia Locale: 'Facoltà riconosciuta dallo stato agli enti pubblici territoriali (regioni, province, comuni) di formulare leggi e di perseguire interessi propri nelle comunità amministrate'. [Facultad reconocida por el Estado a los entes públicos territoriales (regiones, provincias, comunidades) de formular leyes y perseguir intereses propios de la comunidad administrada.] (Garzanti Lingüística, 2007).

2 Aprobada el 19 de noviembre de 1986 y publicada en La Gaceta No. 05 del 9 de enero del siguiente año (1987).

3 Véase el Titulo IX (División Político Administrativa) Capítulo II (Comunidades de la Costa Atlántica) conformado por los artículos 180 y 181.

4 Como eco al artículo 181 de la Constitución Política el cual literalmente se leía "El Estado organizará por medio de una ley, el régimen de autonomía en las regiones donde habitan las Comunidades de la Costa Atlántica para el ejercicio de sus derechos".

5 Conforme al artículo 8 inciso 9 de la Ley No. 28, Estatuto de Autonomía de las Regiones Autónomas de la Costa Atlántica, publicada en La Gaceta No. 238 de 30 de octubre de 1987.

6 En este sentido el artículo 32 del Estatuto de Autonomía de las Regiones Autónomas de la Costa Atlántica dispone que "El Consejo Regional elaborará en coordinación con el Ministerio de Finanzas, el proyecto de presupuesto de su Región Autónoma para el financiamiento de los proyectos regionales (...)"

7 Véase el artículo 23 inc. 2 de la Ley No. 28, Estatuto de Autonomía de las Regiones Autónomas de la Costa Atlántica, publicada en La Gaceta No. 238 de 30 de octubre de 1987.

8 De acuerdo al VIII Censo de Población (INIDE, 2005), la RAAN cuenta con una superficie de 33,105.98 Km² y con una densidad poblacional de $9.5 \mathrm{~h} / \mathrm{km}^{2}$, (lo cual se traduce en 314,507 habitantes); mientras la RAAS representa una superficie de $27,260.02 \mathrm{~km}^{2}$ con una densidad poblacional de $11.2 \mathrm{~h} / \mathrm{km}^{2}$ (equivalente a 305,312 habitantes). Estas cifras son parte fundamental de mi preocupación respecto al tema, ya que estamos hablando de una densidad poblacional extensa.

9 Artículo 18 párrafo tercero de la Ley No. 192, Ley de Reforma Parcial a la Constitución Política de la República de Nicaragua, publicado en La Gaceta No. 124 del 4 de julio de 1995.

10 Reforma hecha por el artículo 12 de la Ley 192 al artículo 140 de inc. 3 de nuestra Constitución.

11 Véase el artículo 6 de la Constitución Política y arto 2 de la Ley No. 28, Estatuto de la Autonomía de las Regiones de la Costa Atlántica de Nicaragua, aprobado el 7 de septiembre de 1987 y publicado en La Gaceta No. 238 de 30 de octubre de 1987.

12 En estos términos se refiere Bermúdez López (2008), quien a su vez afirma que dentro de éstos se incluye erróneamente la recaudación producto de los recursos generados por los tributos provenientes del usufructo y/o explotación de los recursos naturales de las regiones.

13 Esta última afirmación es comúnmente aceptada por la doctrina.

14 Sobre estos conceptos nos referiremos en mayor medida líneas adelante. 
15 Por capacidad contributiva debemos entender la manifestación de riqueza imponible o gravable, definida como la renta, el patrimonio o el gasto o consumo que se realice de parte del contribuyente (Balladares Saballos, 2008).

16 Referido a la idoneidad o aptitud de los contribuyentes para sufragar los gastos públicos (Balladares Saballos, 2007, p.81).

17 Éste consiste en que todos los contribuyentes deben recibir un trato similar frente al mismo hecho imponible (...) tomando en consideración las diferencias que caracterizan la capacidad contributiva de cada persona (Sanabria Ortíz, 1999, p. $360)$.

18 Lo cual hace imposible delegar a los Órganos Regionales por la disposición constitucional citada en el artículo 114.

19 En la terminología jurídica general se suele entender por recargo el incremento contributivo por nueva disposición o de resultas de la mora del contribuyente (Cabanellas de la Cueva \& Ossorio, 2007). Sin embargo, es importante aclarar que los "recargos" a los que nos referiremos no son de carácter sancionatorio o indemnizatorio, por lo cual difieren completamente de los dispuestos en los artículos 17 inc. 6 y 106 inc. 1 de nuestra Ley de Equidad Fiscal, así como el artículo 88 de su Reglamento y 12, 36, 48, 50 y capítulo VI del Código Tributario, ya que éstos se refieren a recargos moratorios 0 sancionatorios en caso de incumplimiento de la obligación tributaria.

20 La justificamos haciendo uso de los fundamentos ya planteados por García Frías (1994, p. 24) citando a Casado Ollero (1987), quien les denomina "sobreimpuestos" tomando como base la traducción de sus homólogos en Derecho comparado, el italiano sovrimposta o el alemán Steverzuschlag, para así, respetar la verdadera naturaleza jurídica de la figura en cuestión evitando confusionismos con otras figuras jurídicas, como el simple aumento de carga a un tributo preexistente.

21 Entiéndase Impuesto sobre la Renta (IR), Impuesto sobre Bienes Inmuebles (IBI), Impuesto al Valor Agregado (IVA), por mencionar algunos comúnmente conocidos.

22 En estos términos se expresa García Frías (1994, p. 55) al delimitar ambas figuras.

23 Véase el Decreto No. 243, Ley Creadora de la Dirección General de Ingreso DGI, publicado en La Gaceta, No. 144 del 29 de junio de 1957; Ley No. 339, Ley Creadora de la Dirección General de Servicios Aduaneros y de Reforma a la Ley Creadora de la Dirección General de Ingresos, publicada en La Gaceta, No. 69 del 6 de abril del 2000; Decreto No. 455, Plan de Arbitrios Municipal, publicado en La Gaceta No. 144 del 31 de julio de 1989; y el Decreto No. 10-91, Plan de Arbitrios del Municipio de Managua, publicado el 12 de febrero de 1991.

24 Entiéndase como tales al Consejo y el Coordinador Regional, en sus respectivas esferas, de acuerdo al arto. 16 de la Ley No. 28, Estatuto de Autonomía de las Regiones Autónomas de la Costa Atlántica, publicada en La Gaceta No. 238 de 30 de octubre de 1987. Sin perder de vista el artículo 28 inc. 1 del Decreto A.N. No.3584, Reglamento a la Ley No. 28, Estatuto de Autonomía de las Regiones de la Costa Atlántica de Nicaragua, publicado en La Gaceta, Diario oficial No. 186 del 02 de octubre del 2003.

25 Recuérdese que siempre deberá ser establecido mediante ley por la Asamblea Nacional.

26 En este caso, por referirnos al Impuesto sobre la Renta, será recaudado por la DGI de acuerdo a su potestad de imposición.

27 Hacemos esta salvedad teniendo presente la reciente reforma tributaria (véase el 4 de la Ley No. 712, Ley de reformas y adiciones a la Ley No. 453, Ley de Equidad Fiscal y a la Ley No. 528, Ley de Reformas y Adiciones a la Ley de Equidad Fiscal, publicada en La Gaceta No. 241 del 21 de diciembre del 2009) que introduce una nueva tabla progresiva para los asalariados, lo cual, me atrevo a afirmar, constituye una manifiesta violación a los principios de justicia tributaria principalmente referente a los principios de capacidad contributiva e igualdad. Sobre esto no entraremos a discusión por motivos metodológicos y porque el tema merece un estudio propio respaldado con fundamentos jurídicos que nos desviarían del tema en cuestión.

28 De conformidad al artículo 28 inc. 1 del Decreto A.N. No. 3584 , Reglamento a la Ley No. 28, Estatuto de Autonomía de las Regiones de la Costa Atlántica de Nicaragua, publicado en La Gaceta, Diario oficial No. 186 del 02 de octubre del 2003.

29 Entiéndase como tal al Impuesto Sobre la Renta conforme lo antes expuesto.

30 Nos limitamos a referirnos en términos de variables ya que el establecimiento del porcentaje idóneo necesita llevar de la mano todo un análisis económico que trasciende los fines del presente estudio jurídico.

31 Entendido como el lugar que el contribuyente escoge de modo particular para el cumplimiento de sus obligaciones tributarias (Sanabria Ortíz, 1999, p. 210). En caso de no ser fijado por el contribuyente se definirá de acuerdo a una serie de criterios establecidos en el articulo 22 del Código Tributario empezando por el lugar que hubiere indicado o registrado la persona natural y/o jurídica al inscribirse en el Registro Único de Contribuyentes de la Administración Tributaria. Ley No. 562, Código Tributario de la República de Nicaragua, publicada en La Gaceta No. 227 del 23 de noviembre del 2005.

32 Debemos recordar que este $1 \%$ fue elegido al azar para ilustrar la propuesta por medio de un caso hipotético, pero reiteramos que para poder determinar un porcentaje, es necesario realizar un estudio económico no incluido en el presente.

33 Subrayamos que el recargo será aplicado sobre la cuota a pagar, ya habiendo realizado todas las deducciones 
correspondientes establecidas mediante ley, según sea el caso.

34 Véase el concepto de origen de renta neta definido por el artículo 4 de la Ley No. 453, Ley de Equidad Fiscal, publicada en La Gaceta No. 82 del 6 de mayo del 2003.

35 Como supuesto hipotético, ya que esta misma cantidad será deducida, por lo cual no será enterada al fisco.

36 Paradójico, pero conveniente para nuestros fines.

37 Sobre este punto existen autores como Enrique Flores, que niegan la posibilidad de una doble imposición a lo interno de un Estado (Flores, 1973, pp. 209-217). Sin embargo, somos de la opinión que en los Estados federados, o aquellos que cuenten con diversas potestades tributarias, ya sea regional, provincial o municipal, coexistiendo una o más potestades tributarias derivadas, siempre existe la posibilidad de coincidencia entre el hecho generador de los tributos nacionales y los regionales o estatales. En el caso de Nicaragua, estando claros que únicamente podemos referirnos a una potestad normativa originaria ostentada por la Asamblea Nacional, siempre existe la posibilidad de crear mediante ley nuevos tributos (ya sea por medio de la Aprobación de Planes de Arbitrio Regionales) a favor de los Gobiernos Regionales que incurran en generar conflictos por posibles coincidencias, coexistiendo una pluralidad de gravámenes sobre la misma manifestación de capacidad contributiva.

\section{Referencias bibliográficas}

Amatucci, A. (dir.). (2001). Trattato di Diritto Tributario: Il concetto di tributo (I parte). Annuario, Padova: Cedam.

Balladares Saballos, R. (2007). Código tributario de Nicaragua. Managua: Lea.

Balladares Saballos, R. (2008). Lección de Derecho Tributario. Manuscrito no publicado, Universidad Centroamericana, Managua, Nicaragua.

Bermúdez López, R. H. (2008). Documento de trabajo del Curso de Práctica Tributaria. Manuscrito no publicado, Universidad Centroamericana.

Cabanellas de la Cueva, G. \& Ossorio y Florit, M. (2007). Diccionario de Derecho. Buenos Aires: Heliasta S.R.L.

Calvo Ortega, R. (1997).Derecho Tributario (parte general): Curso de Derecho Financiero. Madrid: Cívitas.

Escorcia, J. F. (2009). Derecho Administrativo (Primera Parte), Managua: Editorial Jurídica.

Flores, E. (1973). Impuesto sobre la Renta y lo Contencioso Administrativo, San José, Costa Rica: EDUCA.

García Frías, M. de los Á. (1994). La Financiación Territorial Mediante Recargos: Un Análisis Jurídico, Salamanca: Universidad

García-Pelayo \& Gross, R. (1994). Pequeño Larousse Ilustrado 1995. México D.F.: Larousse, S.A.

Garzanti Lingüística. (2007). Dizionari i Garzantini, Trento: De Agostini Scuola S.p.A.

Instituto Nacional de Información de Desarrollo (INIDE). (2005). VIII Censo de Población 2005. Recuperado el 2 de agosto de 2009 de http:/www.inide.gob.ni/censos2005/ censo2005.htm

Moschetti, F. (1973). Il principio della capacità contributiva. Padova: Cedam.

Moschetti, F. (1980). El principio de capacidad contributiva (J. M. Calero Gallego \& R. Navas Vásquez, Trads.). Madrid: IEF.

Pérez Royo, F. (2001). Derecho financiero y Tributario: Parte General. Madrid: Cívitas.

Real Academia Española (RAE). (2001). Diccionario de la Real Academia Española, $12 \mathrm{da}$ ed. Bogotá: Real Academia Española.

Sanabria Ortíz, R. D. (1999). Derecho Tributario e Ilícitos Tributarios. 4ta ed. Lima: Gráfica Horizonte. 


\section{Legislación}

Constitución Política de la República de Nicaragua, publicada en La Gaceta No. 05 del 09 de enero de 1987.

Ley No. 28, Estatuto de Autonomía de las Regiones Autónomas de la Costa Atlántica, publicado en La Gaceta No. 238 de 30 de octubre de 1987.

Ley No. 192, Ley de Reforma Parcial a la Constitución Política de la República de Nicaragua, publicada en La Gaceta No. 124 del 4 de julio de 1995.

Ley No. 339, Ley Creadora de la Dirección General de Servicios Aduaneros y de Reforma a la Ley Creadora de la Dirección General de Ingresos, publicada en La Gaceta, No. 69 del 6 de abril del 2000.

Ley No. 453, Ley de Equidad Fiscal, publicada en La Gaceta No. 82 del 6 de mayo del 2003.

Ley No. 466, Ley de Transferencias Presupuestarias a los Municipios de Nicaragua, publicada en La Gaceta No. 157 del 20 de agosto del 2003.

Ley No. 528, Ley de reformas y adiciones a la Ley No. 453, Ley de equidad fiscal, publicada en La Gaceta No. 104 del 31 de mayo del 2005.

Ley No. 562, Código Tributario de la República de Nicaragua, publicada en La Gaceta No. 227 del 23 de noviembre del 2005.

Ley No. 712, Ley de reformas y adiciones a la Ley No. 453, Ley de Equidad Fiscal y a la Ley No. 528, Ley de Reformas y Adiciones a la Ley de Equidad Fiscal, publicada en La Gaceta No. 241 del 21 de diciembre del 2009.

Decreto No. 243, Ley Creadora de la Dirección General de Ingreso DGI, publicado en La Gaceta, No. 144 del 29 de junio de 1957.

Decreto No. 455, Plan de Arbitrios Municipal, publicado en La Gaceta No. 144 del 31 de julio de 1989.

Decreto No. 10-91, Plan de Arbitrios del Municipio de Managua, publicado el 12 de febrero de 1991.

Decreto No. 46-2003, Reglamento de la Ley No. 453, Ley de Equidad Fiscal, publicado en La Gacetas No. 109 y 110 del 12 y 13 de junio del 2003.

Decreto A.N. No.3584, Reglamento a la Ley No. 28, Estatuto de Autonomía de las Regiones de la Costa Atlántica de Nicaragua, publicado en La Gaceta, Diario oficial No. 186 del 02 de octubre del 2003. 